\title{
Ensaio sobre a interação cidadania-trabalho: desafios e perspectivas para a (in)compreensão da cidadania social no Brasil
}

\author{
Essay on citizenship-work interaction: challenges and perspectives for the (in) \\ comprehension of social citizenship in Brazil
}

\author{
Narice Flaviana de Souza Alves Barbosa Braz* \\ Jailton Macena de Araújo**
}

\section{Resumo}

No presente artigo se faz uma análise comparativa da evolução do conceito de cidadania, ao tempo em que se analisa em que medida o trabalho estabelece íntima ligação com ela, no sentido de viabilizador de inclusão social, aprimorando o patamar de democracia social. Parte-se do princípio de que os indivíduos não só desejam serem membros da sociedade, como também querem seu reconhecimento enquanto membros, no afã de serem respeitados enquanto tal. Assim, ressalta-se que, através da garantia de direitos e liberdades civis, políticos e sociais, extensivos a todos, em igualdade formal e substancial, combate-se a marginalização/exclusão de determinadas categorias de cidadãos apenas formalmente considerados, a exemplo dos desempregados - cidadãos restritos. Para tanto, realiza-se uma incursão pela cidadania como fenômeno histórico, tal qual originada nas cidades-Estado clássicas, sobretudo na ateniense, pela pensada por Thomas Humprey Marshall, e, por fim, pela brasileira, revisitada por José Murilo de Carvalho, utilizando-se o método dedutivo e, como meio técnico de investigação, o monográfico.

Palavras-chave: Democracia. Cidadania. Inclusão social. Direitos sociais. Trabalhadores proletários.

\section{Abstract}

In the present article a comparative analysis of the evolution of the concept of citizenship is made, at the same time as it analyzes the extent to which work establishes an intimate connection with it, in the sense of enabling social inclusion, improving the level of social democracy. It is assumed that individuals not only wish to be members of the Society, but also want their recognition as members, in the desire to be respected as such. Thus, it is emphasized that by ensuring rights and civil, political and social liberties, extensive for all, in formal and substantive equality, attackes the marginalization and exclusion of certain categories of citizens only formally considered, like the unemployed - restricted citizens. For this, in the article it's done an incursion for the citizenship, like historical phenomenon, as originated in the classic city-states, above all, in Athenian; according Thomas Humprey Marshall; and, finally, by the Brazilian, revisited by José Murilo de Carvalho, using the deductive method and as a technical means of investigation, the monographic.

Keywords: Democracy. Citizenship. Social inclusion. Social rights. Proletarian workers.

\section{Introdução}

A relevância das reflexões sobre cidadania e o seu exercício se torna cada dia mais evidente. Das digressões clássicas até a compreensão contemporânea, a cidadania tem abrangido diversas perspectivas, sempre sendo estabelecida a partir das necessidades, interesses e percepções dos sujeitos sociais.

$O$ ideal de cidadania surgiu na Antiguidade, tendo passado por significativas mudanças durante a Idade Média, até sua conceituação na modernidade. Classicamente, a cidadania remonta ao cotidiano

\footnotetext{
Mestranda em Direito Econômico pela Universidade Federal da Paraíba - UFPB. Professora EBTT do Instituto Federal de Educação, Ciência e Tecnologia da Paraíba - IFPB. João Pessoa - PB - Brasil. E-mail: naricesouza@gmail.com.

Doutor e Mestre em Ciências Jurídicas pela Universidade Federal da Paraíba. Professor do Curso de Direito, vinculado ao Departamento de Direito Processual e Prática Jurídica (DDPPJ), do Centro de Ciências Jurídicas (CCJ) da Universidade Federal da Paraíba. Docente Permanente do Programa de Pós-Graduação em Ciências Jurídicas da UFPB. Editor-gerente da Prim@Facie, Revista do PPGCJ/UFPB. João Pessoa - PB - Brasil. E-mail: jailtonma@gmail.com.
} 
das polis gregas; em especial, o observado em Atenas. Ali, um modo de vida que pressupôs a educação dos indivíduos para a manifestação da palavra apropriada na esfera pública foi desenvolvida a fim de que a influência pessoal e direta nos assuntos do Estado pudesse ser estendida a todos aqueles que se encontravam inclusos nos pré-requisitos que os qualificavam como cidadãos.

Tempos mais tarde (sem a pretensão de estabelecer-se uma rigidez quanto aos períodos históricos), na Europa, anota-se o contexto de ruptura com uma sociedade que negava as liberdades individuais, valorizando organismos coletivos. tais como a Igreja e o Império, a família e a comunidade, bem como a agricultura. Verificou-se a ascendência de um novo modelo de sociedade centrada no homem, no fortalecimento do comércio, atrelada ao nascimento dos Estados nacionais e que pressupôs uma remodelagem da cidadania (outrora desaparecida, quando do período absolutista).

Essa nova roupagem social europeia revisitou as bases da cidadania e abriu as portas para a formação de um laço de identidade entre o nacional e o Estado-nação, muito embora tenha dado lugar, assim como em Atenas, ao estabelecimento e imposição de exigências, características ou requisitos para a participação cidadã dos indivíduos, como a propriedade, a ascendência divina, a escolaridade e o sexo, por exemplo, obstando a ampliação do status de cidadão a todos.

Assim, "possuir cidadania", conforme critérios de julgamento estabelecidos pelos mais elevados extratos sociais, passou a ser determinante quando do estabelecimento da posição hierárquica que os membros de determinada sociedade ocupavam dentro dela e viceversa: a posição hierárquica que os membros ocupavam no seio social era determinante para que possuíssem o status de cidadania.

Atualmente, o Brasil e o mundo ocidental presenciam, em graus de intensidade não necessariamente idênticos entre os países, uma cidadania que passou a alcançar (ao menos formalmente), camadas da população que se encontravam segregadas. Todavia isso não se refletiu em igualdade entre "iguais" dentro do mesmo Estado, nem mesmo a expressão cidadania passou a refletir um conteúdo equânime, conforme adverte José Murilo de Carvalho (2015, p. 18): "Quando (sic.) falamos de um cidadão inglês, ou norteamericano, e de um cidadão brasileiro, não estamos falando exatamente da mesma coisa".

A restrição na cidadania, através da não participação de camadas da população politicamente e economicamente "dispensáveis" ou "irrelevantes" (a exemplo dos analfabetos e trabalhadores desempregados), revela a impressão de que a cidadania não é instrumento de igualdade, mas forte mecanismo de promoção de desigualdade no meio social. Diante dessa evidência, pretende-se percorrer os elementos que compõem as discussões sobre a cidadania ao longo do tempo, de modo a correlacionar a ideia de cidadania social, de Marshall, à compreensão de cidadania pautada no trabalho, como parte de uma construção democrática e cidadã.

É nesse sentido que se problematiza: é possível se falar de cidadania diante da condição de exclusão social e econômica que aflige tantos sujeitos sociais? Parte-se, aqui, da premissa de que a orientação de cidadania contemporânea está atrelada à realização plena dos direitos civis, políticos, sociais e econômicos dos sujeitos sociais, buscando-se, através da perspectiva histórica, os elementos que respondam satisfatoriamente a essa indagação.

\section{A cidadania original: apontamentos históricos e teóricos sobre participação política}

O conceito de cidadania remonta à participação direta e pessoal dos cidadãos nas cidades-Estado clássicas gregas estabelecidas "perenemente", no período que data aproximadamente do século VIII ou VII a.C ao século IV a. C, dentre as quais se destaca, comumente, Atenas. Cardoso (1985) destaca ao menos duas das características comuns que apresentavam as poleis:

1) Do ponto de vista formal, a tripartição do governo em uma ou mais assembléias, um ou mais conselhos, e certo número de magistrados escolhidos - quase sempre anualmente- entre os homens elegíveis; 2) a participação direta dos cidadãos no processo político: a noção de cidade-Estado implica a existência de decisões coletivas, votadas depois de discussão (nos conselhos e/ou nas assembléias), que eram obrigatórias para toda a comunidade, o que quer dizer que os cidadãos com plenos direitos eram soberanos (CARDOSO, 1985, p. 8). 
Para que a soberania da cidadania nas cidades-Estado possa ser abordada, devem ser desprestigiados os períodos autoritários, monarcas e dominados por governos estrangeiros, ainda que nas cidades helenísticas e no Império Romano, durante a monarquia, certo grau de participação tenha sido atribuído aos cidadãos, haja vista que às cidades-Estado fora concedida certa margem de autogoverno, o que insinua que, na democracia, os cidadãos do período clássico conseguiram estabelecer uma maior "soberania cidadã".

Não obstante isso, nessas democracias clássicas, os escravos, as mulheres e os estrangeiros residentes permaneciam excluídos da participação política, e os líderes políticos eram provenientes, geralmente, da aristocracia, o que implicava que, mesmo naquelas sociedades, já se observava a superioridade de determinados grupos hegemônicos (mesmo que entre "cidadãos" em franca igualdade política), assim como a legitimação da desigualdade social.

As cidades-Estado significavam, para o cidadão, que o mesmo passaria, obrigatoriamente, de agente de sua própria vida doméstica a ocupante de outra vida, dessa vez, política (através da ação - praxis; e do discurso- lexis), a ser exercida na esfera pública da polis. No cotidiano dos cidadãos, essas "duas vidas" se excluíam mutuamente, a depender de em qual esfera da vida estavam a participar em determinado momento.

Interessante anotar a passagem que Arendt (1995) discorre sobre o respeito que as polis manifestavam para com a vida dos cidadãos, mantendo-se o equilíbrio entre a esfera privada e a pública:

O que impediu que a polis violasse as vidas privadas dos seus cidadãos e a fez ver como sagrados os limites que cercavam cada propriedade não foi o respeito pela propriedade privada tal como a concebemos, mas o fato de que, sem ser dono de sua casa, o homem não podia participar dos negócios do mundo porque não tinha nele lugar algum que lhe pertencesse. (ARENDT, 1995, p. 39).

Vale ressaltar, portanto, que aos cidadãos das cidades-Estado era esclarecida a importância da propriedade privada para a sua vida, ao tempo em que a capacidade para o exercício de funções públicas e para as tomadas de decisão na democracia ateniense, por exemplo, era presumida: os cidadãos (iguais que eram) já as conheciam e as possuíam, naturalmente.

No entanto Hobbes (apud WALZER, 2003, p. 417), tomando por base o modelo estabelecido na assembleia ateniense, em que não havia propriamente uma igualdade entre os cidadãos e um governo do "povo", coloca que a democracia naquele tempo não passava de "uma aristocracia de oradores, às vezes interrompida pela monarquia temporária de um orador".

A cidadania em Atenas era, portanto, um status que implicava na diferenciação entre os indivíduos, com a garantia de direitos que possibilitavam participação ativa de significativo número de membros sobre as decisões políticas e a exclusão dos demais indivíduos, tidos como comuns.

A participação cidadã em Atenas se dava através da oralidade dos discursos e debates nos espaços públicos, o que implicava que a igualdade de direitos políticos não era posta em prática integralmente, haja vista que, mesmo entre os cidadãos, havia aqueles com maior participação e influência - os privilegiados.

Ademais, com o crescimento do território por meio da incorporação de novas terras e novos povos, as cidades-Estado gregas inviabilizaram o funcionamento do exercício da cidadania através da democracia direta, no plano prático, pois a participação personalíssima e exercida diretamente na realização dos debates que antecediam a votação ou durante a votação propriamente dita restou prejudicada.

Portanto, muito embora haja a contribuição dessas sociedades antigas para o delineamento da cidadania tal qual ela é concebida atualmente (com busca pela participação igualitária), algumas das camadas que, até hoje, encontram-se fortemente deslocadas da participação cidadã também o eram na Antiguidade.

É isso o que se observa no trecho abaixo, no qual se lê que, em linhas gerais, as cidades-Estado gregas viviam a realidade de que as melhores terras estavam concentradas nas mãos da "aristocracia de sangue", detentora também do poder político e judiciário, na medida em que:

[...] os lotes dos camponeses pobres, devido a contínuas partilhas sucessórias, podiam chegar a tamanhos ínfimos [...]. Havia ainda, o empréstimo in natura (sobretudo de cereais) que os proprietários mais ricos faziam aos camponeses pobres, do qual podia resultar a perda da terra pelos últimos, 
continuando o ex-dono a trabalhar a parcela, agora como arrendatário; e mesmo uma forma de escravidão ou servidão por dívidas, já que o pagamento destas era garantido pela pessoa do devedor e de seus familiares. (CARDOSO, 1985, p. 24).

Nessas circunstâncias, tem-se o alinhamento entre a cidadania embrionária e a desigualdade social, sem denotar o desprezo, por certo, do papel evolutivo que essas sociedades galgaram, a seu modo, em direção à igualdade entre os indivíduos.

\section{A cidadania social: de Thomas Humprey Marshall à (in)compreensão da cidadania social brasileira}

O sociólogo T. H. Marshall (1967) revisita criticamente a ideia de cidadania desenvolvida pelo economista Alfred Marshall ${ }^{1}$ (1842-1924), de modo a estabelecer um parâmetro próprio de cidadania para a sociedade inglesa.

Alfred Marshall (1949), na sua obra, tentou avaliar a possibilidade de as classes trabalhadoras se desenvolverem, não se referindo à escassez dos recursos naturais ou se a produtividade seria deficiente, mas sim a respeito da existência de algum limite que restringiria o progresso dessa categoria. Seu ensaio "foi construído com base numa hipótese sociológica e num cálculo econômico" (MARSHALL, 1967, p. 61).

Marshall A. (apud MARSHALL, 1967), mesmo não acreditando que todos os homens pudessem ser iguais (inclusive quantitativamente), vislumbra que, através da educação e da ocupação, todo homem pudesse tornar-se um cavalheiro, ainda que em um processo vagaroso. Nesse sentido, pensava que a via do trabalho árduo e em excesso era, em verdade, um empecilho para que qualquer trabalhador se tornasse um cavalheiro.

Ele apostava na redução do trabalho a ínfimas parcelas, a serem desempenhadas por todos os membros do seio social. Apesar de seu pensamento se aproximar de um discurso ideológico socialista, ele defendia que os indivíduos eram os únicos responsáveis por se tornarem cavalheiros. Para ele, era fundamental a preservação da liberdade de mercado, sem a atuação interventiva do Estado para a consecução de "direitos de cidadania". (MARSHALL, 1967).

A par disso, Thomas Marshall (1967) desenvolve sua ideia de cidadania apoiando-a em três elementos: civil, político e social, associando-os a períodos formativos: séculos XVIII, XIX e XX, respectivamente. Ele assevera que essa associação deve ser encarada com ressalvas dentro do contexto inglês, haja vista que a cronologia demonstra apenas um sentimento de que um ou outro elemento tenha se enraizado mais em um período histórico do que nos outros.

\subsection{Esboço teórico da cidadania social Marshalliana}

$\mathrm{Na}$ Inglaterra, o conceito de cidadania se estendeu a outras esferas que não exclusivamente a seara do direito civil, muito embora haja o alerta para o fato de que os três elementos estavam entrelaçados enquanto as funções do Estado assim também permaneceram. A partir do momento em que foram criadas instituições estatais e nacionais, cada qual responsável por garantir a efetividade de cada elemento especificamente, houve a ruptura dos três elementos e suas "evoluções" se processaram de maneira individualizada e diferenciada. (MARSHALL, 1967).

Os Tribunais de Justiça passaram a ser responsáveis por garantir os direitos civis (liberdade de pensamento, de propriedade e de locomoção, por exemplo); os Parlamentos e os Conselhos assegurariam os direitos políticos, através da participação dos indivíduos no exercício do poder político (como eleitos ou como eleitores); e o Sistema educacional e serviços sociais garantiriam a cidadania social (bem-estar econômico, segurança, "direito de participar da herança social e ser civilizado"). (MARSHALL, 1967, p. 63-66).

1 Ainda que o termo cidadania não seja citado expressamente por Alfred, que se atem ao termo "cavalheiro", a fim de distinguir o não trabalhador cavalheiro do trabalhador não cavalheiro - este último, a ser inserto no seio social aos moldes dos padrões civilizatórios da sociedade inglesa de sua época. (MARSHALL, 1967, p. 61). 
Todo o desenho que se estabeleceu em torno dos elementos da cidadania serviu: i) para que houvesse a decisão sobre quais direitos seriam reconhecidos aos cidadãos; e, principalmente, ii) para estabelecer em que medida os cidadãos poderiam usufruir desses direitos.

Notório, entretanto, que os direitos civis foram os mais arduamente reivindicados, pois representavam tanto a defesa dos indivíduos contra as arbitrariedades dos Estados com ranço absolutista como deveriam servir ao sistema capitalista em expansão, sendo "urgente a consolidação da tradicional família burguesa centrada no patriarcado, no princípio da propriedade privada e no inalienável direito a herança". (GERMANO, 2011, p. 112).

Pari passu, portanto, novos direitos individuais foram sendo incrementados a uma cidadania limitada que já existia e que não assegurava universalmente, já nos idos do século XIX, os direitos políticos, tratandoos como um atributo do homem adulto que ocupava uma classe econômica privilegiada.

[...] o núcleo da cidadania, nesta fase, se compunha de direitos civis. E os direitos civis eram indispensáveis a uma economia de mercado competitivo. Davam a cada homem, como parte de seu status individual, o poder de participar, como uma unidade independente, na concorrência econômica, e tornaram possível negar-Ihes a proteção social com base na suposição de que o homem estava capacitado a proteger-se a si mesmo. (MARSHALL, 1967, p. 79).

Todavia os direitos civis não representaram uma melhoria no padrão de vida dos "cidadãos" de extratos sociais inferiores, a ponto de Marshall $(1967$, p.80) acrescentar que:

Um direito de propriedade não é um direito de possuir propriedade, mas um direito de adquiri-la, caso possível, e de protegê-la, se se puder obtê-la. Mas caso se lance mão dêsses argumentos para explicar a um pobre que seus direitos de propriedade são os mesmos daqueles de um milionário, provàvelmente o indigente nos acusará de estar sofismando.

Os direitos sociais de cidadania, que permaneciam sendo renegados na Europa, ao ponto de serem "confundidos" com as poor laws inglesas, surgiram como uma necessidade de adaptar a renda dos cidadãos às suas reais necessidades, mas foram encarados como um afronta ao costume da época de entender a ajuda estatal não como um direito dos cidadãos, mas como uma escolha pela desistência da condição de cidadão. Era o fracasso do indivíduo que não conseguiu prosperar em um ambiente "favorável" à mobilidade social. A cidadania, entendida como capacidade, poderia ser negada aos incapazes, sendo-lhes negado ou retirado o status de cidadania.

Não obstante isso, no século XIX, com o triunfo da burguesia industrial, do capitalismo e das crises próprias do modelo estabelecido, surgiu uma nova classe de trabalhadores, os "proletários", como percebidos por Karl Marx (1848), como uma classe que passou a questionar o capitalismo burguês, opondo-se ao individualismo reinante, à miséria, à precarização das condições de vida e de trabalho, e aos desígnios das elites para governar.

O questionamento da classe proletária fez repensar o progresso social como algo individual, a ser obtido através de direitos civis, em detrimento daquele a ser alcançado via estabelecimento de direitos sociais, que aliviam as desigualdades, sobretudo econômicas, promovendo inclusão.

Diante disso, o desenvolvimento da sociedade, que nunca pode ser considerado individual, passou a ser um valor a ser compartilhado entre seus membros, o que ajudou a consolidar um novo Estado, intitulado de Estado de bem-estar social, na Europa.

Cumpre salientar, tanto os direitos civis quanto os direitos políticos foram fundamentais para o consenso de que os indivíduos encontravam-se habilitados a titularizarem outros direitos de cidadania e que, através dos direitos políticos, poderiam ampliar ou exigir que o Estado reconhecesse um padrão civilizatório a todos (MARSHALL, 1967).

Ao longo dos séculos XVIII, XIX e XX, tomando-se por base, nesse instante, o recorte cronológico proposto por T. H. Marshall (1967), a cidadania passou a significar para as massas, simplificadamente, "igualdade perante a lei". Essa "igualdade" fez com que uma massiva camada da população pudesse ser 
titular de direitos e obrigações em determinados Estados, o que não impediu o florescimento de extensa gama de cidadãos "restritos", formalmente incluídos, mas materialmente alijados da cidadania plena.

\section{2 contraponto da cidadania brasileira: a deturpação política da cidadania nos processos sociais e econômicos no Brasil}

É no reconhecimento da existência dos cidadãos "restritos" que o historiador e cientista político José Murilo de Carvalho (2015) afirma que a gênese da cidadania brasileira diverge em muito do modelo histórico de cidadania inglesa proposta por Marshall (1967), pelo fato de que, no Brasil, os direitos sociais foram aqueles que ocuparam a dianteira, tendo surgido antes que os direitos de cidadania civis e políticos despontassem.

Para Carvalho (2015), a colonização portuguesa teve papel fundamental para essa cronologia, pois projetou uma sociedade que, desde seu processo de independência até o início da Primeira República, não possuía "cidadãos brasileiros", nem uma "pátria brasileira", pois os indivíduos não conseguiram forjar com o Estado uma íntima relação que predispusesse os laços afirmadores da cidadania, haja vista que Portugal impusera um país dotado de unidade territorial, linguística, cultural e religiosa, com uma sociedade escravocrata, de economia monocultora, latifundiária e população quase que integralmente rural e analfabeta (CARVALHO, 2015, p. 24).

Do processo colonizatório resultou que os índios foram dizimados, os escravos não tinham direito algum e a população livre se concentrou em torno do projeto econômico imposto por Portugal, por meio do comércio do açúcar, da mineração de pedras preciosas e da criação de gado. As grandes distâncias entre a colônia e o reino português transformaram os proprietários (homens livres) da zona interiorana em autoridades arbitrárias dentro de suas propriedades e para com todos que se estabeleciam em derredor, a quem eram negados os mínimos direitos civis - o que produziu problemas sociais que ainda persistem na sociedade brasileira.

A situação de analfabetismo generalizado, que se aliou à associação estabelecida entre grandes proprietários e autoridades públicas, criou o ambiente propício para uma ausência de consciência e de exercício prático da cidadania.

A independência do Brasil, ocorrida em 1822, é outro momento citado por Carvalho (2015) como determinante para a precária cidadania brasileira que se verifica posteriormente: foi um movimento negociado entre as elites (que temiam que as instabilidades pudessem inflar eventuais movimentos revolucionários das classes sociais renegadas), sem guerra armada. Não se pode negar que, embora algumas vezes possam ser traumáticos, os conflitos bélicos podem ser salutares para o reforço de laços de fidelidade, pertencimento e lealdade entre os indivíduos e o Estado, algo muito caro para o estabelecimento da consciência da identidade cidadã - o que, de forma ampla, é capaz de gerar rupturas reais com o sistema de exploração das elites, jamais ocorreu no Brasil.

Depois da independência, a educação foi deixada de lado ou prestada de maneira insatisfatória, porque era vista como poderosa arma cívica. Portugal não permitia o funcionamento de universidades na colônia, tendo sido estabelecidas escolas superiores somente em 1808, com a chegada da família real no Brasil (CARVALHO, 2015).

Os direitos políticos da cidadania, no caso brasileiro, partem na frente dos direitos civis e acompanham um processo de expansão formal, com a inclusão de uma gama considerável de "cidadãos" no aparato da cidadania, para "acalmá-los". Muito embora o voto fosse censitário, o critério de renda era baixo e não excluía a população pobre do direito de voto, porém:

Os brasileiros tornados cidadãos pela Constituição eram as mesmas pessoas que tinham vivido os três séculos de colonização nas condições que já foram descritas. Mais de $85 \%$ eram analfabetos, incapazes de ler um jornal, um decreto do governo, um alvará da justiça, uma portaria municipal. Entre os analfabetos incluíam-se muitos dos grandes proprietários rurais. Mais de $90 \%$ da população vivia em áreas rurais, sob o controle ou a influência dos grandes proprietários. Nas cidades, muitos votantes eram funcionários públicos controlados pelo governo. (CARVALHO, 2015, p. 37-38). 
Nesse sentido, as eleições a "bico de pena" ou "voto de cabresto" se tornaram a regra no Brasil, sendo marcantes durante o fenômeno do coronelismo, verificado fortemente da República Velha até a Revolução de 1930, conforme o controle direto ou indireto do direito de votar, estabelecido pelas elites de maneira violenta, o que fazia perpetuar uma participação política das massas de assalariados e camponeses apenas com o especial fim de manter o cenário de profundas desigualdades sociais e de reafirmação do poder dos governantes, sem a preocupação de difusão do ideal de cidadania.

Os direitos políticos, formalmente estabelecidos, não puderam representar a essência da cidadania em seu elemento político, nem se prestar à representação/autogoverno da população, se tornando um "faz de conta". Tomando as lições de Rousseau, Walzer (2003, p. 419) coloca que, na democracia, "[...] o poder político é distribuído por meio de debates e votos", mas que esse poder é diferente daquele capaz de decidir "destinos e riscos", pois, na democracia, ao invés do que ocorre na aristocracia, o voto das massas tem pouco poder de influência.

Carvalho (2015) alerta que pode haver direitos políticos sem direitos civis, mas não pode haver direitos civis sem direitos políticos. Por isso, na realidade brasileira, os direitos civis deixaram de ser estabelecidos à esmagadora parcela da população, que continuara a sofrer as consequências do estabelecimento de direitos políticos desnaturados. A reboque da realidade, Walzer (2003, p. 419) argumenta que o voto livre e consciente tem um papel maior na democracia, haja vista que:

'Um cidadão/um voto' é o equivalente funcional, na esfera da política, do regime contra a exclusão e a degradação na esfera do bem-estar social, do princípio da consideração igual na esfera dos cargos, e da garantia de uma vaga na escola para cada criança na esfera da educação. É o alicerce de todas as atividades distributivas e a estrutura inescapável dentro da qual é preciso fazer as escolhas.

A afirmação da consciência de titularidade dos direitos sociais restou, assim, prejudicada, posto que os direitos sociais se afiguraram no contexto de formação da cidadania brasileira. A ideia de exercício da cidadania brasileira, falha desde sua origem, funcionou como um meio para tentar acobertar as falhas da cidadania precária e exposta através da cooptação das classes "cidadãs" desfavorecidas, verdadeiras telespectadoras e intérpretes de um panorama de pobreza, miséria e indigência, que não possuíam autonomia em seus direitos civis e políticos.

\section{Cidadania, trabalho e inclusão: desafios e perspectivas}

Em incursão histórica, Assis (2002) esclarece que o trabalho, no Brasil e no mundo, ficou atrelado e, de certo modo, renegado pelas iniciativas das primeiras democracias modernas dos EUA e da França, que, no século XIX, priorizaram a propriedade como forjadora de suas Cartas políticas. Ele assevera que apenas a propriedade teve papel crucial nessa dinâmica de construção da cidadania, muito embora ambos (trabalho e propriedade) mantivessem íntima relação com o capitalismo emergente, dado que o capital privatizou os meios de produção, separando-os dos trabalhadores.

O direito de propriedade, encarado como sinônimo de liberdade política dos indivíduos em relação ao Estado, passou a ser o requisito principal para obtenção da cidadania embrionária naqueles países e ao redor do mundo ocidental a partir de então e durante largo período em diante.

É interessante notar que a democracia estadunidense transformou indivíduos em cidadãos através da aquisição de terras obtidas via doação (excluídos desse processo, por óbvio, os índios). A França, por sua vez, transformou indivíduos em cidadãos facilitando a compra de terras após a Revolução Francesa (1789-1799). A igualdade foi afirmando-se, em ambos os casos, através da propriedade.

No caso americano, com as doações, uma inclusão maior de pessoas no espectro da cidadania se operou, ao tempo em que, na França, o acesso à propriedade através da compra e venda deixou de fora uma gama expressiva de pessoas (ASSIS, 2002).

Parece ser um questionamento evidente e atrelado ao que se discute neste momento saber se o Estado moderno, forjado na propriedade, traduz-se em ambiente de garantia, não só da igualdade civil e política, mas também da igualdade social à classe trabalhadora e não proprietária. 
É sabido que o viés social da cidadania (MARSHALL, 1967), sobretudo no tocante ao direito ao trabalho no mundo moderno, vem a reboque das lutas das classes sociais desfavorecidas ao longo do século $X X$, mediante reivindicações, sobretudo, de trabalhadores que não possuíam terras ou propriedade, que trocavam sua força de trabalho por salário e que há longo tempo haviam permanecido renegados à situação de restrição de sua cidadania, quer seja em sua concepção formal, quer seja em sua concepção substancial.

Arendt (2007), quando lança o conceito de vita activa (sinônimo de três atividades da vida humana: labor, trabalho e ação), ressalta o desvalor dado ao labor e ao trabalho ao longo da tradição. Não obstante isso, a autora preza pela relevância de cada um desses componentes para o ser humano e lança luz sobre o porquê da prevalência da ação sobre os demais, ao afirmar que:

O labor assegura não apenas a sobrevivência do indivíduo, mas a vida da espécie. O trabalho e seus produtos, o artefato humano, emprestam certa permanência e durabilidade à futilidade da vida mortal e ao caráter efêmero do tempo humano. A ação, na medida em que se empenha em fundar e preservar corpos políticos, cria a condição para a lembrança, ou seja, para a história. (ARENDT, 2007, p. 16-17).

Não se pode negar que a correlação entre o labor, parte da sobrevivência humana, o trabalho, responsável pela produção dos excedentes, e a ação, capaz de tornar o homem um sujeito político, faz preponderar a existência humana como parte de uma compreensão maior da própria cidadania. Assim, pode-se aduzir, consoante Assis (2002), ponderando a respeito do papel das instituições governamentais no atendimento dos direitos sociais, que precisam ser "influenciadas" pela participação cidadã de autogoverno, que:

\begin{abstract}
O direito ao trabalho remunerado, mesmo quando protegido constitucionalmente, como no Brasil, não tem uma contrapartida específica que obrigue que ele seja satisfeito pelo setor privado ou pelo setor público empregador. Ele se traduz, analiticamente, como direito coletivo a uma política pública de promoção do pleno emprego. Certamente, só o Estado dispõe de instrumentos de política econômica para criar condições favoráveis ao pleno emprego no mercado de trabalho. (ASSIS, 2002, p. 20, grifos do original).
\end{abstract}

Neste ponto, cumpre salientar que a utilização de avaliações coletivas pelos grupos dominantes, de modo a legitimar a exclusão legal ou costumeira, não mais se sustenta, pois elas representam odiosa forma de atentado contra a cidadania e contra o estado democrático de direito, que deve assegurar a plena participação do povo.

As avaliações coletivas nem sempre demonstram respeito aos direitos sociais (aos direitos humanos, até - apenas mencionados aqui de forma a enfatizar o desrespeito corriqueiro àqueles), haja vista que podem ser sinônimo dos interesses de parcela da população que possui poder de influência cidadã e que não está diretamente envolvida na indignidade da miserabilidade.

No contexto neoliberal, o planejamento e a intervenção do Estado no campo social se traduz como intenção totalitária, antilibertária e antidemocrática (MALAGUTI, 2000, p. 61).

Ao Estado caberia o papel de se fazer restrito, facilitando a vida dos empreendedores privados, garantindo apenas a infraestrutura (para a redução dos custos de mercadorias), a existência de hospitais públicos (que reduzam as ausências ao emprego), a propriedade privada (assegurada pela polícia ou pelo exército), a justiça (que garanta o cumprimento dos contratos e a propriedade) e escolas básicas (que instruam o trabalhador apenas no que é requerido para o desempenho mínimo da atividade nas empresas, sem formar por inteiro o cidadão). Qualquer tipo de intervenção diferente dessa seria considerada uma ameaça à liberdade econômica e política responsável pelas crises do sistema capitalista. A essa evidência, Durkheim (1960, p. 275-276) exarou:

Com efeito, em todo momento da história existe um sentimento obscuro, na consciência moral das sociedades, acerca do valor respectivo aos diferentes serviços sociais, da remuneração merecida por cada um e, consequentemente, do grau de conforto apropriado, em média, aos trabalhadores de cada ocupação. As diferentes funções são hierarquizadas pelas opiniões e um certo coeficiente de bem-estar é atribuído a cada uma, de acordo com a posição que ocupa na hierarquia. 
Por outro lado, a constatação de que os direitos de cidadania são descasados de pragmatismo tão somente em relação a parcelas desfavorecidas, servindo ao propósito de manutenção da desigualdade no exercício de poder, de favorecimento de competição deletéria, de segregação de indivíduos e de dominação dos homens uns pelos outros, traz como consequência questionamentos profundos que desestabilizam o ambiente democrático (exatamente aquele que mais favorece o exercício da liberdade e da igualdade, valores próprios da cidadania), pois, afinal de contas, "a inclusão é aconselhada pela máxima medieval, bastante defendida pelos democratas modernos: O que toca a todos deve ser decidido por todos." (WALZER, 2003, p. 399, grifos do original).

Corroborando com esse ideário, Marshall (1967, p. 77) coloca que a desigualdade de classes sociais é, em certa medida, "necessária e proposital", porque "incentiva o esforço e determina a distribuição de poder". A pobreza das camadas inferiores obrigaria, via de regra, a que os indivíduos pobres se tornassem produtivos, o que, segundo ele, é extremamente positivo para o desenvolvimento do corpo social.

Por outro lado, quando funções públicas são exercidas por pessoas determinadas, elas ocupam, fatalmente, assim como nas cidades-Estado clássicas, uma posição de superioridade hierárquica perante os demais.

A expansão do capital implicou, em um primeiro momento, em uma necessidade de mão de obra, que foi, a despeito da inclusão precária no mercado, relegada a espaços geográficos periféricos nas polis, configurando novos elementos de exclusão social e objeto de novas políticas sociais, que teriam o fito primordial de arrefecer tensões sociais geradas pelos conflitos sociais que acabam por exigir do poder público cada vez mais subsídios para o acesso aos direitos sociais, como a mobilidade urbana e o acesso à educação e aos empregos.

Não obstante os argumentos sugestivos de que a negativa de cidadania plena a determinadas classes sociais é inevitável e que haveria uma impossibilidade de igualdade material entre os cidadãos, quiçá entre os indivíduos, não se pode desprezar a conjuntura constitucional de igualdade de condições estabelecida entre os cidadãos (de viés político) e o caráter de mandamento constitucional dado aos direitos sociais e impelido aos Estados (que se traduz no reconhecimento de valores sociais de solidariedade, justiça social e proteção da dignidade humana).

A materialização dos direitos sociais através de normas de direito trabalhista, por exemplo, conforma outros vieses da vida em sociedade, como educação, meio ambiente, infância, habitação, alimentação, saúde, assistência aos necessitados, lazer, além de outros direitos encarados tipicamente como civis: liberdade, igualdade e propriedade (CORREIA; SOUTO MAIOR, 2007).

Dentre os direitos sociais, o direito ao trabalho é inegável instrumento de inclusão participativa, conectando o cidadão que trabalha ao desenvolvimento, enquanto sujeito ativo que gera riqueza e produz bens e serviços, ao tempo em que movimenta o mercado de consumo. O processo de exclusão/integração no contexto capitalista funciona, como bem observa Faleiros (1988, p. 45), como "[...] um sistema político de mediações que visam à articulação de diferentes formas de reprodução das relações de exploração e dominação da força de trabalho entre si, com o processo de acumulação e com as forças políticas em presença".

O cidadão-trabalhador diminui as barreiras econômicas existentes entre as classes sociais, bem como as barreiras culturais de participação e contribuição, propiciando o usufruto do bem-estar, envolvido no processo de construção do progresso social, a todos os cidadãos e suas famílias. Assim, o acesso do cidadão-trabalhador aos benefícios decorrentes do desenvolvimento no meio social é, portanto, legítimo e possui elevado nível de justiça. O direito ao trabalho é, desse modo, "instrumento de concretização de inserção social", bem como

fator de bem-estar também psicológico e emocional. A dignidade do trabalhador, através do exercício de sua atividade laboral, traduz-se pelo conforto material, pelo reconhecimento profissional, pela autoestima do trabalhador e, finalmente, pela estabilidade em todos os seus aspectos. (CECATO, 2012, p. 27-28).

Como mazela decorrente da restrição de cidadania, o desemprego nega ou inviabiliza quase que completamente o acesso do indivíduo ao desenvolvimento, porque lhe é negado o ganho material que lhe 
permite seu sustento e o de sua família, o bemestar amplo e a integração social dele ao corpo social, devendo o Estado oferecer-lhe oportunidades de participar, contribuir e usufruir do desenvolvimento, eliminando quaisquer ou eventuais obstáculos, ou seja, garantindo direitos sociais que auxiliem não só no equilíbrio de sua renda, mas na garantia da dignidade cidadã. Nesse sentido, Araújo (2018, p. 136), ao afirmar que:

\begin{abstract}
O direito e o Estado devem desempenhar um papel de reestruturação dos valores sociais que tenham na cidadania e na participação social sua base. Semelhante formulação decorre da compreensão da função central das políticas sociais, que é a melhoria das condições de vida dos cidadãos brasileiros. A principal característica da proteção dos direitos sociais é o reconhecimento da hipossuficiência da grande maioria de cidadãos pobres que se encontram à margem da economia e da realização dos direitos sociais, que tem no trabalho a sua origem.
\end{abstract}

Em outra banda, o subjugo dos direitos sociais ao direito civil de propriedade traz uma incongruência inaceitável, uma vez que os direitos civis poderiam representar uma escala hierárquica de importância que não se justifica. Nesse ponto, Correia e Souto Maior (2007, p. 15) asseveram:

Assim, se o direito de propriedade pudesse subjugar todos os demais direitos, passando a ser princípio, - e mais, sobreprincípio- seria possível se deslocar, indevidamente, a proteção do homem (destinatário do direito) para a propriedade (objeto do direito). A inversão possibilita o esdrúxulo, mas não incomum, posicionamento da propriedade como destino de 'todas as coisas' em direito, quando a vocação é o bem do homem.

É fato que o Brasil contemporâneo sofreu mudanças estruturais e políticoinstitucionais que resultaram em uma incorporação de massas à economia de mercado e ao sistema político democrático, revertendo expectativas pessimistas que davam conta de que a mobilidade social ascendente seria limitada e improvável, bem como que a estratificação social se manteria como nas décadas de 80 e 90 , quando o consumo era restrito a pequenos nichos populacionais devido à alta concentração da renda, ocasionada prioritariamente pela exclusão social e política.

Porém as crises cíclicas do capitalismo parecem, a todo instante, colocar na berlinda dos direitos, os sociais, indo na contramão do entendimento de que o bem-estar social e os diretos sociais, entre os quais se destaca o dos trabalhadores, em verdade, servem ao próprio capital e são fundamentais para que o sistema seja conservado. É nesse sentido, que, nas palavras de Araújo (2018, p. 148), afirma-se que:

Especialmente em razão das complicações decorrentes da crise econômico-financeira atual, as possibilidades históricas, aventadas para o Estado Social clássico, têm se perdido diante da degradação das contas públicas e da necessidade de substituição do Estado Providência por uma compreensão mais ampla da cidadania.

Consoante a isso, a democracia também resta em risco sempre que longos períodos de desemprego se instalam e os serviços sociais estão dispostos de maneira precária ou ineficiente, pois os trabalhadores sem renda e sem alternativa tendem a desacreditar nos mecanismos democráticos, apostando em governos autoritários e populistas, que se colocam como sensíveis à causa popular e capacitados a eficazmente e rapidamente solucioná-la. Delgado (2006, p. 142-143), ao se referir ao direito do trabalho, no Brasil, como instrumento de civilização e "garantidor de significativo patamar de democracia social" compreende que:

[...] há uma singularidade no desenvolvimento econômico-social brasileiro: aqui, em torno de somente $1 / 3$ dos trabalhadores ocupados é regido pelo Direito do Trabalho, em contraponto com o percentualpadrão de mais de $80 \%$ de relevantes países capitalistas. [...] Tudo isso demonstra ainda haver largo espaço para atuação do Direito do Trabalho no Brasil, como instrumento civilizatório fundamental para a construção da democracia social e também da cidadania neste País.

Desse modo, os países capitalistas em que o padrão civilizatório se estabeleceu creditam ao direito do trabalho o papel de valorização do trabalho e do cidadão trabalhador, e de regulação do modelo de produção capitalista, visando justiça social, o que demonstra que o trabalho inclui para a cidadania democrática. Deve, pois, para haver uma revitalização da esfera laboral, haver uma ampliação da sua abrangência de proteção, eminentemente no Brasil, em favor das classes sociais mais desfavorecidas quanto ao exercício da cidadania. 
É evidente que referida construção dialógica entre trabalho e cidadania permitiria um fortalecimento de ambas as instituições sociais em benefício da dignidade humana dos sujeitos mais vulneráveis.

\section{Considerações finais}

Em um caminho ascendente, a cidadania moderna passou a ganhar contornos de um atributo ou um "superdireito", que abriu a possibilidade de titularização e aquisição de outros direitos e procurou igualar formalmente os indivíduos, mitigando a imposição de barreiras segregadoras, como aquelas existentes no nascedouro da cidadania grega, abrindo a possibilidade de massiva participação e integração de membros na sociedade e nas decisões políticas nacionais.

Nesse sentir, a utilização da cidadania desvirtuada de sua função de promoção da igualdade social e a coexistência, em uma sociedade, de cidadãos formalmente livres e iguais, mas divididos por desigualdades socioeconômicas profundas, causa clamor social e a constatação de uma concepção política de injustiça, que não fomenta a cooperação equitativa entre os indivíduos, as expectativas de reciprocidade entre todos e um consenso sobreposto a respeito de eventual medida de usufruto da cidadania (RAWLS, 2011).

Nesse contexto de cidadania moderna formal, no qual não há um parâmetro que oriente os limites ou o patamar mínimo de direitos e obrigações que devem ser atribuídos ao status de cidadania, acaba por gerar um déficit de participação efetivo. A cidadania formal, como mencionado, é estendida e alargada a uma gama da população historicamente privada de participação nos assuntos do Estado, as quais assim permanecem, diante dos desníveis de acesso às oportunidades sociais, o que nos leva a concluir, com segurança, que a ideia de cidadania plena (formal + substancial) ainda não se operou. Dessa forma, visualizou-se verdadeira cisma entre o exercício da cidadania substancial por todos os cidadãos e a realidade de desigualdades.

Apesar da mudança substancial porque vem passando a cidadania, a ampliação formal de seus elementos não levou automaticamente ao exercício de todos os direitos, o que trouxe uma inquietude e um desconserto diante da constatação de que ela não se apresentou como solução para os problemas sociais de miséria e indignidade.

Lamentavelmente, ao longo da história, constata-se que os cidadãos não possuem o mesmo poder de influência, muito embora todos participem em algum momento ou em alguma medida dos processos decisórios, pois "é provável que a decisão democrática perfeita se aproxime mais dos desejos dos cidadãos que tenham mais habilidade política. A política democrática é monopólio dos políticos”. (WALZER, 2003, p. 417).

A política brasileira, em sua essência, é marcada por uma disputa distributiva entre classes sociais que vivenciam processos de mobilidade social, recheada de tolerância às transgressões que a marcaram. Assim, a cidadania brasileira, igualada à participação política, passou a ter importância ímpar e a alimentar o debate atual sobre se a igualdade formal da cidadania no Brasil se restringe, ainda que ironicamente, à igualdade política e civil.

É forçoso concluir que as classes proletárias da atualidade brasileira, integrantes de extratos sociais com baixa escolaridade, com alta carga horária de trabalho semanal ou desempregadas e sem oportunidades de engajamento nas questões políticas, permanecem em uma realidade em que leis são aprovadas, em grande parte, afinadas com os desejos das classes dominantes (proprietárias) e que, tradicionalmente, já estão incluídas no seio social, perpetuando o regime de extrema desigualdade entre as classes sociais.

Desse modo, a garantia e a reafirmação da cidadania extensiva a todos se fazem necessárias, tendo em vista que há, na imposição de restrições à participação cidadã, para além da marginalização, pobreza e miséria decorrentes, o sentimento em ebulição de que inexistem razões legítimas para que essas restrições sejam aceitas, especialmente na camada dos excluídos, fato que coloca em perigo a democracia.

Acredita-se que é de interesse geral do povo que haja existência digna propiciada a todos os membros da sociedade e é certo que a democracia (entre os regimes de governo até hoje existentes) se mostra o sistema ideal para que a participação cidadã ocorra, sendo, portanto, o meio apropriado para que a busca pela dignidade humana se opere. 
Assim, a compreensão acima mencionada de cidadania plena necessita ser irrestritamente concretizada (para todos os cidadãos, sem que se mantenham os desníveis de acesso e exercício dos direitos), especialmente tomando como consideração o conjunto de direitos e garantias fundamentais inscritos nos textos constitucionais dos mais variegados Estados, especialmente, naqueles em desenvolvimento. A cidadania, assim, deve se traduzir, atualmente, em igualdade (de direitos e de obrigações civis, políticas e sociais), garantindo a participação dos cidadãos na contribuição para o usufruto do progresso, do bem-estar social, do desenvolvimento na sua tripla acepção: econômica, social e ambiental, bem como de herança da nação.

Nesse mister, o direito ao trabalho é, indubitavelmente, um mecanismo que assegura ao cidadãotrabalhador e à sua família efeito distributivo de poder e renda no contexto socioeconômico e que atua diretamente na autonomia plena dos indivíduos enquanto valor social a ser realizado na esfera pública, garantindo direitos e liberdades, assim como o ideal de justiça.

\section{Referências}

ARAUJO, Jailton Macena de. Constituição, cidadania e trabalho: premissas para o reconhecimento de uma racionalidade estatal pautada na solidariedade. Direito, Estado e Sociedade, Rio de Janeiro, n. 52, p. 134-158, jan./jun. 2018.

ARENDT, Hannah. A condição humana. Rio de Janeiro: Forense Universitária, 1995.

ASSIS, José Carlos de. Trabalho como direito: fundamentos para uma política de promoção do pleno emprego no Brasil. Rio de Janeiro: Contraponto, 2002.

CARDOSO, Ciro Flamarion. A cidade estado antiga. São Paulo: Ática, 1985. (Série Princípios).

CARVALHO, José Murilo de. Cidadania no Brasil: o longo caminho. Rio de Janeiro: Civilização Brasileira, 2015.

DAHL, Robert. A democracia e seus críticos. Tradução: Patrícia Freitas Ribeiro. São Paulo: Martins Fontes, 2008.

DELGADO, Maurício Godinho. Capitalismo, trabalho e emprego: entre o paradigma da destruição e os caminhos da reconstrução. São Paulo: LTr, 2006.

DURKHEIM, Émile. Da divisão do trabalho social. Tradução: Eduardo Brandão. São Paulo: Martins Fontes, 1999.

FALEIROS, Vicente de Paula. O que é política social. 3. ed. São Paulo: Brasiliense, 1988. (Col. Primeiros passos).

GERMANO, Marcelo Gomes. Uma nova ciência para um novo censo comum. Campina Grande: EDUEPB, 2011.

MARSHALL, Thomas Humphrey. Cidadania, classe social e status. Rio de Janeiro: Zahar, 1967. MARX, K.; ENGELS, F. Manifesto do Partido Comunista. 9. ed. Petrópolis, RJ: Vozes, 1999.

RAWLS, Jonh. O liberalismo político. Tradução: Dinah de Abreu Azevedo. São Paulo: Ática, 2000.

WALZER, Michael. Esferas da justiça: uma defesa do pluralismo e da igualdade. São Paulo: Martins Fontes, 2003.

Recebido em: 13/03/2019

Aprovado em: 24/04/2020 